\title{
Casca de Café em Dietas de Carneiros: Consumo e Digestibilidade ${ }^{1}$
}

\author{
Alexandre Lima de Souza ${ }^{2}$, Rasmo Garcia ${ }^{3}$, Fernando Salgado Bernardino ${ }^{4}$, Fernanda Cipriano \\ Rocha $^{4}$, Sebastião de Campos Valadares Filho ${ }^{3}$, Odilon Gomes Pereira ${ }^{3}$, Aureliano José Vieira Pires ${ }^{5}$
}

RESUMO - Avaliaram-se o consumo e a digestibilidade aparente de dietas contendo 0,0; 6,25; 12,5; 18,75 e 25\% de casca de café, em base da MS, em substituição ao milho na ração concentrada. Foram utilizados 20 carneiros, sem raça definida, distribuídos em um delineamento em blocos casualizados, com cinco tratamentos e quatro repetições. As dietas isoprotéicas, com 10\% de proteína bruta (PB), foram constituídas de $60 \%$ de feno de capim-coastcross e $40 \%$ de ração concentrada, em base da MS. Os animais foram mantidos em gaiolas de estudos metabólicos por 19 dias (12 de adaptação e sete de coletas). Os consumos de matéria seca (MS), matéria orgânica (MO), PB, carboidratos totais (CT), fibra em detergente neutro (FDN), carboidratos não-fibrosos (CNF) e nutrientes digestíveis totais observados (NDT) não foram influenciados pelos níveis de casca de café utilizados, observando-se valores médios de 1,41; 1,34; 0,15; 1,16; 0,71, 0,45; e 0,85 kg/dia, respectivamente. As digestibilidades aparentes da MS, MO, PB, FDN, CT e CNF não foram influenciadas pelos níveis de casca de café utilizados, registrando-se valores médios de 60,1; 62,1; 66,3; 46,9; 61,5 e 84,1\%, respectivamente. A casca de café pode ser incluída em até 25,0\% na dieta de ovinos, substituindo o milho da ração concentrada.

Palavras-chave: composição químico-bromatológica, ração concentrada, resíduo agroindustrial

\section{Coffee Hulls in the Diet of Sheep: Intake and Apparent Digestibility}

\begin{abstract}
Four levels of coffee hulls (0.0, 6.25, 12.5, 18.75 and 25.0\% DM) in substitution of ground corn in their concentrate ration were used to evaluate the effects on intake and apparent digestibility of diets. Twenty, unknown breed, sheeps were used in a randomized block design, with five treatments and four replicates. The animals were fed all ad libitum with isoprotein diets, $10 \%$ crude protein (CP), contained $60 \%$ of coastcross hay and $40 \%$ of concentrate in dry matter basis. Sheep were maintained in a metabolism cage for 19 days (12 days of adaptation and 7 days of data collection). The intakes of dry matter (1.41), organic matter (1.34), CP (0.15), total carbohydrate (1.17), neutral detergent fiber (0.71) and nonfiber carbohydrate (0.45) and the total digestible nutrients $(0.85) \mathrm{kg} /$ day were not affected by the coffee hulls levels. Coffee hulls did not affect apparent digestibility of dry matter (60.1\%), organic matter (62.1\%), neutral detergent fiber (46.9\%), CP (66.3\%), total carbohydrate (61.5\%) and nonfiber carbohydrate (84.1\%). Coffee hulls can be included up to $25 \%$ in the concentrate ration.
\end{abstract}

Key Words: agroindustrial residue, chemical-bromatologic composition, concentrate ration

\section{Introdução}

A estacionalidade na produção de forragens em determinadas épocas tem sido responsável, dentre outros fatores, pela reduzida produtividade dos rebanhos que, em conjunto com a freqüente variação dos preços dos grãos de cereais e suplementos protéicos utilizados na alimentação animal, tem despertado o interesse no aproveitamento de alimentos alternativos.

Nesse contexto, os resíduos da agroindústria podem assumir um importante papel na alimentação dos ruminantes, principalmente em situações, em que: a) a disponibilidade natural de forragens nas pastagens é baixa, b) as reservas de forragens conservadas forem insuficientes para atenderem as necessidades dos rebanhos, c) na formulação de misturas múltiplas para animais em pastejo, ou d) ainda quando a disponibilidade, valor nutritivo e o custo do resíduo permitirem sua inclusão na formulação de rações concentradas, substituindo de forma parcial alimentos nobres comumente utilizados.

Os subprodutos ou resíduos da agroindústria podem apresentar características de alimentos fibrosos, como bagaço de cana-de-açúcar e palhadas, ou de alimentos concentrados, como polpa cítrica, casca e farinha de mandioca, caroço de algodão, casca de

\footnotetext{
${ }^{1}$ Projeto financiado pela Fundação de Amparo a Pesquisa do Estado de Minas Gerais (FAPEMIG).

2 Zootecnista, D.Sc., Professor do Departamento de Ciências Biológicas/Zootecnia - UFMT. E.mail: alex-Is@pop.com.br

3 Professor do Departamento de Zootecnia - UFV, Bolsista do CNPq.

4 Zootecnista, M.Sc., DZO/UFV (fsbernadino@ibest.com.br).

5 Professor do Departamento de Tecnologia Rural e Zootecnia - UESB (aureliano@uesb.br).
} 
soja e farelo de arroz. Entretanto, dependendo da constituição da dieta, das características intrínsecas e da forma em que é fornecido, um determinado resíduo pode se comportar de forma distinta. Nesse caso, pode-se citar a casca de café, resíduo proveniente do beneficiamento do grão, que vem sendo utilizada em algumas pesquisas substituindo tanto alimentos volumosos (Townsend et al., 1998; Vilela, 1999) quanto grãos de cereais (Barcelos et al. 1997), podendo ainda ser utilizada como aditivo na produção de silagens de gramíneas tropicais (Souza et al., 2003).

Entre os resíduos agroindustriais existentes, a casca de café encontra-se disponível em diversos estados brasileiros, sendo que só no Estado de Minas Gerais, responsável por, aproximadamente, $44 \%$ da produção nacional, são produzidos anualmente 1.637.645 t de café (Anuário Estatístico do Brasil, 2000), que podem gerar ao final de seu processamento mais de 800.000 t de casca, considerando a relação de café beneficiado e casca de 1:1 (Bártholo et al., 1989).

A adição de casca de café, em substituição aos grãos de cereais da ração concentrada de ruminantes ou mesmo de animais monogástricos (Oliveira, 2001), representa uma possibilidade de reduzir custos com alimentação dos rebanhos. Todavia, esta análise deve ser acompanhada de uma avaliação criteriosa dos efeitos da inclusão da casca, entre outros, sobre o consumo e a digestibilidade que podem afetar o desempenho e a saúde dos animais. Em alguns estudos realizados com ovinos, avaliou-se apenas a inclusão deste resíduo em substituição a forragens (Townsend et al., 1998) ou ao milho desintegrado com palha e sabugo (Garcia et al., 2000), não sendo estudada sua substituição em relação ao milho.

Diante do volume de casca de café que anualmente é produzido no Brasil, da carência de trabalhos de pesquisas e das necessidades de identificar níveis de inclusão na dieta de ruminantes que possam permitir melhor utilização deste resíduo, conduziu-se este experimento objetivando avaliar os efeitos da adição de casca de café na ração concentrada, em substituição ao fubá de milho, sobre o consumo e a digestibilidade aparente da matéria seca e dos nutrientes.

\section{Material e Métodos}

O experimento foi conduzido no Departamento de Zootecnia da Universidade Federal de Viçosa, em Viçosa, MG, no período de 28 de abril a 16 de maio de
2000. Avaliaram-se o consumo e a digestibilidade aparente da MS e dos nutrientes de dietas contendo diferentes níveis de casca de café $(0,0 ; 6,25 ; 12,5$; 18,75 e $25 \%$ da MS) em substituição ao milho na ração concentrada, que corresponderam aos níveis de 0,$0 ; 2,5 ; 5,0 ; 7,5$ e 10,0\% de casca de café na MS da dieta total, respectivamente.

Vinte carneiros adultos, sem raça definida, castrados, foram mantidos em gaiolas de estudos metabólicos por 19 dias (12 de adaptação e sete de coleta), quando foram registrados os consumos de alimentos e realizadas as coletas de fezes. Os animais foram pesados no início e final do experimento. Após pesagem inicial, os animais foram transferidos para gaiolas de estudos metabólicos dotadas de bebedouro e comedouros, para fornecimento de alimentos e sal mineral, efetuando-se, em seguida, a vermifugação dos mesmos. O experimento foi conduzido em um delineamento em blocos casualizados, com quatro repetições, sendo cada animal considerado uma unidade experimental e os blocos formados de acordo com o peso dos animais.

Os animais receberam dietas contendo $60 \%$ de feno de capim-coastcross, e $40 \%$ de ração concentrada, formulada com milho, farelo de soja e casca de café. As dietas isoprotéicas com, aproximadamente, $10 \%$ de PB, conforme recomendações do National Research Council (1985) para mantença dos animais, foram fornecidas ad libtum, duas vezes ao dia, sempre às 07 e 16 horas, permitindo sobras de 5 a $10 \%$. A mistura entre o volumoso e a ração concentrada foi realizada no momento do fornecimento da alimentação. Os animais tiveram ainda acesso a uma mistura mineral fornecida, ad libitum, em cocho separado. A composição percentual dos ingredientes das rações concentradas encontra-se na Tabela $1 \mathrm{e}$ a composição químico-bromatológica do volumoso, casca de café e das rações concentradas, na Tabela 2.

A amostragem dos alimentos oferecidos, das sobras e suas quantificações, para posteriores análises e determinação do consumo foi realizada no período do $13^{\circ}$ ao 19 음 dia do experimento. Durante o mesmo período, procedeu-se à coleta total de fezes, utilizando bolsas coletoras de couro adaptadas aos animais. A digestibilidade aparente da MS e dos nutrientes foi calculada pelo método direto, ou seja, pela diferença entre consumido e excretado. Durante a coleta e pesagem das excreções fecais, realizadas sempre às 8 e $17 \mathrm{~h}$, foram retiradas amostras equivalentes a $5 \%$ do peso. Amostras dos alimentos fornecidos, das

R. Bras. Zootec., v.33, n.6, p.2170-2176, 2004 (Supl. 2) 
Tabela 1 - Composição percentual dos componentes das dietas

Table 1 - Percentual composition of ingredients on diets

\begin{tabular}{lccccc}
\hline & \multicolumn{5}{c}{ Dietas $^{1}$} \\
& Diets \\
\cline { 2 - 6 } $\begin{array}{l}\text { Componentes } \\
\text { Ingredients }\end{array}$ & 0,0 & 6,25 & 12,5 & 18,75 & 25,0 \\
\hline $\begin{array}{l}\text { Feno } \\
\text { Hay }\end{array}$ & 60,0 & 60,0 & 60,0 & 60,0 & 60,0 \\
$\begin{array}{l}\text { Milho } \\
\text { Corn }\end{array}$ & 32,9 & 30,3 & 27,7 & 25,1 & 22,5 \\
$\begin{array}{l}\text { Farelo de soja } \\
\text { Soybean meal } \\
\text { Casca de café }\end{array}$ & 7,1 & 7,2 & 7,3 & 7,4 & 7,5 \\
\begin{tabular}{l} 
Coffee hulls \\
\hline
\end{tabular} & 0,0 & 2,5 & 5,0 & 7,5 & 10,0 \\
\end{tabular}

${ }^{1}$ Níveis de casca de café na ração concentrada (Coffee hulls levels on concentrate ration).

2 Porcentagem na MS da dieta (DM percentage on diets). sobras e das fezes foram acondicionadas em sacos plásticos e guardadas em freezer para posteriores análises. As amostras do feno, casca de café, sobras e fezes foram pré-secas em estufa de ventilação forçada a $60^{\circ} \mathrm{C}$, durante 72 horas. Em seguida, foram homogeneizadas para confecção das amostras compostas por animal e moídas em moinho tipo Willey, utilizando-se peneira de $1 \mathrm{~mm}$.

A casca de café foi adquirida de indústria beneficiadora, localizada no sul do Estado de Minas Gerais. Nessa indústria, o processamento do café é realizado por via seca. Antes de ser misturada aos ingredientes da ração concentrada, a casca de café foi processada em moinho tipo martelo, com peneira semelhante à utilizada na moagem do milho.

Tabela 2 - Composição químico-bromatológica do feno, da casca de café e das rações concentradas Table 2 - Chemical-bromatologic composition of the hay, coffee hulls and concentrate rations

\begin{tabular}{|c|c|c|c|c|c|c|c|}
\hline \multirow[t]{2}{*}{$\begin{array}{l}\text { Itens } \\
\text { Items }\end{array}$} & \multirow[t]{2}{*}{$\begin{array}{l}\text { Feno de capim-coastcross } \\
\text { Coastcross hay }\end{array}$} & \multirow[t]{2}{*}{$\begin{array}{c}\text { Casca de café } \\
\text { Coffee hulls }\end{array}$} & \multicolumn{5}{|c|}{$\begin{array}{c}\text { Concentrado }^{1} \\
\text { Concentrate }\end{array}$} \\
\hline & & & 0,0 & 6,25 & 12,5 & 18,75 & 25,0 \\
\hline MS \% (DM) & 86,0 & 86,2 & 86,3 & 86,3 & 86,2 & 85,8 & 85,9 \\
\hline $\mathrm{MO}^{2}(\mathrm{OM})$ & 93,6 & 94,4 & 97,8 & 97,6 & 97,2 & 96,9 & 96,6 \\
\hline $\mathrm{PB}^{2}(C P)$ & 6,0 & 6,9 & 15,2 & 15,3 & 15,3 & 15,6 & 15,8 \\
\hline $\operatorname{NIDN}^{3}(N D I N)$ & 66,2 & 34,7 & 4,6 & 5,4 & 6,1 & 6,8 & 7,6 \\
\hline $\operatorname{NIDA}^{3}(A D I N)$ & 11,9 & 24,4 & 2,5 & 3,6 & 4,9 & 5,8 & 7,2 \\
\hline $\mathrm{EE}^{2}$ & 1,33 & 1,8 & 4,1 & 3,0 & 2,7 & 2,3 & 1,9 \\
\hline $\mathrm{CT}^{2}(\mathrm{TC})$ & 86,3 & 85,7 & 78,5 & 79,3 & 79,2 & 79,0 & 78,9 \\
\hline $\mathrm{FDN}^{2}(N D F)$ & 77,7 & 59,4 & 11,1 & 13,7 & 16,1 & 18,3 & 22,8 \\
\hline $\mathrm{FDNCp}^{2}\left(N D F_{c p}\right)$ & 72,1 & 55,6 & 10,2 & 12,5 & 14,8 & 16,9 & 20,7 \\
\hline $\mathrm{CNF}^{2}(N F C)$ & 14,2 & 30,1 & 68,3 & 66,8 & 64,4 & 62,1 & 58,2 \\
\hline $\mathrm{FDA}^{2}(A D F)$ & 35,6 & 42,4 & 3,5 & 5,1 & 7,4 & 9,2 & 13,6 \\
\hline FDAi (iADF) & 14,7 & 37,7 & - & - & - & - & - \\
\hline Lignina $^{2}$ (Lignin) & 5,4 & 12,0 & 0,4 & 0,7 & 1,5 & 2,3 & 3,4 \\
\hline $\mathrm{Ca}^{2}$ & 0,66 & 0,33 & 0,12 & 0,17 & 0,15 & 0,13 & 0,16 \\
\hline $\mathrm{P}^{2}$ & 0,22 & 0,07 & 0,30 & 0,30 & 0,31 & 0,27 & 0,26 \\
\hline $\mathrm{K}^{2}$ & 1,90 & 2,39 & 0,73 & 0,8 & 0,94 & 1,02 & 1,19 \\
\hline $\mathrm{Na}^{2}$ & 0,02 & 0,04 & - & - & - & - & - \\
\hline $\mathrm{Mg}^{2}$ & 0,05 & 0,03 & 0,05 & 0,04 & 0,05 & 0,04 & 0,04 \\
\hline $\mathrm{NDT}_{\mathrm{EST}}{ }^{2,4}\left(\mathrm{TDN}_{E S T}\right)$ & 53,5 & 50,4 & 87,7 & 85,5 & 82,6 & 80,6 & 76,2 \\
\hline
\end{tabular}

${ }_{1}^{1}$ Porcentagem de casca de café na ração concentrada, em base da MS.

1 Percentage of coffee hulls on concentrate ration, DM basis.

2 Valores em porcentagem da MS.

${ }^{2}$ Values in DM base.

${ }^{3}$ Valores em porcentagem do nitrogênio total.

3 Values in the percentage of total nitrogen.

${ }^{4}$ Valores estimados, NRC (2001)

${ }^{4}$ Estimated values, NRC (2001).

MS, MO, PB, NIDN, NIDA, EE, CT, FDN, FDN , CNF, FDA, FDAi e NDT-Matéria seca, matéria orgânica, proteína bruta, nitrogênio insolúvel em detergente neutro, nitrogênio insolúvel em detergente ácido, extrato etéreo, carboidratos totais, fibra em detergente neutro, fibra em detergente neutro corrigida para cinzas e proteína, carboidratos não-fibrosos, fibra em detergente ácido, fibra em detergente ácido indigestível e nutrientes digestíveis totais estimados.

$D M, O M, C P, N D I N, A D I N, E E, T C, N D F, N D F_{C p}, N F C, A D F, i A D F, T D N$ - dry matter, organic matter, crude protein, neutral detergent Insoluble nitrogen, acid detergent Insoluble nitrogen, ether extract, total carbohydrate, neutral detergent fiber, neutral detergent fiber without ash and protein, non fiber carbohydrate, acid detergent fiber, indigestible acid detergent fiber and total digestible nutrients. 
As análises de matéria seca (MS), matéria orgânica (MO), nitrogênio total, fibra em detergente neutro (FDN), fibra em detergente ácido (FDA), lignina e extrato etéreo (EE), nitrogênio insolúvel em detergente neutro (NIDN) e nitrogênio insolúvel em detergente ácido (NIDA) foram realizadas segundo os procedimentos descritos por Silva e Queiroz (2002). Os teores de carboidratos totais (CT) foram calculados segundo as equações propostas por Sniffen et al. (1992).

Os teores de nutrientes digestíveis totais estimados $\left(\mathrm{NDT}_{\mathrm{EST}}\right)$ dos alimentos, rações concentradas e dietas totais foram calculados conforme equações descritas pelo National Research Council (2001). Para o cálculo do NDT $_{\text {EST }}$ do volumoso e da casca de café, utilizou-se a equação: $\mathrm{NDT}_{\text {EST }}=0,98\left[100-\left(\% \mathrm{FDN}_{\mathrm{p}}+\% \mathrm{~PB}+\% \mathrm{EE}+\right.\right.$ \%cinza) $]$ x PF + PB x exp [ -1,2 x (PIDA/PB) $]+2,25$ $\mathrm{x}(\mathrm{EE}-1)+0,75 \mathrm{x}\left(\mathrm{FDN}_{\mathrm{p}}\right.$ - Lignina $) \mathrm{x}[1$ - (Lignina/ $\left.\mathrm{FDN}_{\mathrm{p}}\right)^{0,667}$ ] - 7 e para o cálculo do $\mathrm{NDT}_{\mathrm{EST}}$ das rações concentradas, a equação: $\mathrm{NDT}_{\mathrm{EST}}=0,98$ $\left[100-\left(\% \mathrm{FDN}_{\mathrm{p}}+\% \mathrm{~PB}+\% \mathrm{EE}+\%\right.\right.$ cinza $\left.)\right] \mathrm{x} \mathrm{PF}+\mathrm{PB}$ $\mathrm{x} \exp [-0,4 \mathrm{x}(\mathrm{PIDA} / \mathrm{PB})]+2,25 \mathrm{x}(\mathrm{EE}-1)+0,75$ $\mathrm{x}\left(\mathrm{FDN}_{\mathrm{p}}\right.$ - lignina) $\left.\mathrm{x}\left[1 \text { - (lignina/FDN }{ }_{\mathrm{p}}\right)^{0,667}\right]$ - $7 \mathrm{em}$ que, nas equações acima: FDN $_{p}=$ FDN - PIDN (PIDN = nitrogênio insolúvel em detergente neutro $\mathrm{x}$ 6,25); $\mathrm{PF}=$ efeito do processamento físico na digestibilidade dos carboidratos não-fibrosos; PIDA = nitrogênio insolúvel em detergente ácido x 6,25. Para valores de $\mathrm{EE}<1$, na equação $(\mathrm{EE}-1)=0$.

Para o feno, a casca de café e os concentrados, utilizou-se valor de PF igual a 1. Os valores de nutrientes digestíveis totais observados foram calculados para as diferentes dietas pela equação:

$$
\mathrm{NDT}=\mathrm{PBD}+\mathrm{EED} \times 2,25+\text { FDND }+ \text { CNFD }
$$

em que PBD = proteína bruta digestível; EED = extrato etéreo digestível; FDND = fibra em detergente neutro digestível; $\mathrm{CNFD}=$ carboidratos não-fibrosos digestíveis.

Os resultados foram submetidos às análises de variância e de regressão, adotando-se o nível de significância de 5\%, utilizando-se o Programa SAEG, versão 7.1 (UFV, 1997). A escolha do melhor modelo foi feita com base no coeficiente de determinação e na significância dos coeficientes de regressão, utilizando-se o teste "t", de Student, a 5\% de probabilidade.

\section{Resultados e Discussão}

A concentração de nutrientes digestíveis totais estimadas $\left(\mathrm{NDT}_{\mathrm{EST}}\right.$ ) da casca de café de $50,4 \%$ foi 3,6 unidades percentual inferior ao valor de $\mathrm{NDT}_{\mathrm{EST}}$ por Baião (2002). Grande parte da diferença entre os valores de NDT estimados para a casca de café pode ser explicada pela variação na concentração de FDN e lignina observada em diferentes pesquisas (Barcelos et al., 1997; Souza et al. 2002; Vilela, 1999). A variabilidade registrada na composição químicobromatológica da casca de café pode ser atribuída a diferentes fatores - cultivares, condições de cultivo e operações empregadas durante o processamento do grão, que podem resultar em casca de café de diferente valor nutritivo.

Os valores médios relativos aos consumos diários de matéria seca (MS), matéria orgânica (MO), proteína bruta (PB), extrato etéreo (EE), carboidratos totais (CT), fibra em detergente neutro (FDN), carboidratos não-fibrosos (CNF) e nutrientes digestíveis totais (NDT) com as suas equações de regressão são apresentados na Tabela 3. A análise de regressão não detectou efeito dos níveis de casca de café sobre os consumos diários de MS e MO, expressos em g/dia e em \% do PV, e sobre o consumo de PB, expresso em g/dia. Observou-se valores médios de 1412, 1342 g/dia e de 3,03 e 2,88\% PV para os consumos diários de MS e MO, respectivamente e consumo diário de 149 g de PB. Resultados semelhantes foram relatados por Garcia et al. (2000) para consumo de MS e PB em ovinos recebendo $200 \mathrm{~g}$ de silagem de capim-elefante e concentrados, fornecido ad libtum, contendo casca de café in natura ou tratada com $4 \%$ de uréia, substituindo em 15\% o milho desintegrado com palha e sabugo (MDPS). O consumo médio diário de matéria seca de $78,5 \mathrm{~g} / \mathrm{kg}^{0,75}$ registrado neste experimento foi semelhante aos $77,0 \mathrm{~g} / \mathrm{kg}^{0,75}$ verificados por aqueles autores.

O consumo médio diário de MS de casca de café foi de 0,$0 ; 35,67,116$ e 134 g para os animais que receberam rações concentradas contendo 0,0 ; 6,$25 ; 12,5 ; 18,75$ e $25 \%$ deste resíduo, respectivamente, que, por sua vez, corresponderam aos níveis de 0,$0 ; 2,5 ; 5,0 ; 7,5$ e 10,0\% de casca de café na MS da dieta.

A análise de regressão não detectou efeito dos níveis de casca de café sobre os consumos diários de CT, FDN e CNF, expressos em g/dia e em \% do PV, 
Tabela 3 - Peso médio (PM) e variação de peso de animal vivo (VPV), e consumos médios de matéria seca (MS) e dos nutrientes das dietas em função dos níveis de casca de café na ração concentrada (base da MS), coeficiente de variação $(C V)$ e equações de regressão

Table 3 - Body weight (BW) and body weight variation of the animals and mean intake of dry matter (DM) and nutrients in function of coffee hulls levels on concentrate rations (DM base), coefficient of variation and regression equations

\begin{tabular}{|c|c|c|c|c|c|c|c|}
\hline \multirow[t]{2}{*}{$\begin{array}{l}\text { Itens } \\
\text { Items }\end{array}$} & \multicolumn{5}{|c|}{$\begin{array}{l}\text { Dietas } \\
\text { Diets }\end{array}$} & \multirow[t]{2}{*}{$\mathrm{CV}$} & \multirow[t]{2}{*}{$\begin{array}{l}\text { Equações de regressão } \\
\text { Regression equations }\end{array}$} \\
\hline & 0,0 & 6,25 & 12,5 & 18,75 & 25,0 & & \\
\hline $\mathrm{PV}, \mathrm{kg}(B W)$ & 48,2 & 49,3 & 48,1 & 49,3 & 48,1 & & \\
\hline \multicolumn{8}{|c|}{$\begin{array}{l}\text { Consumo, g/dia } \\
\text { Intake, g/day }\end{array}$} \\
\hline MS (DM) & 1445 & 1388 & 1336 & 1554 & 1338 & 23,2 & $\hat{Y}=1412$ \\
\hline MO (OM) & 1378 & 1321 & 1269 & 1476 & 1267 & 23,2 & $\hat{\mathrm{Y}}=1342$ \\
\hline $\mathrm{PB}(C P)$ & 148 & 147 & 143 & 161 & 143 & 22,6 & $\hat{\mathrm{Y}}=149$ \\
\hline $\mathrm{EE}$ & 37,8 & 30,4 & 27,7 & 28,1 & 22,5 & 25,2 & $\hat{\mathrm{Y}}=35,91-0,5283 \mathrm{X}\left(\mathrm{r}^{2}=0,94\right)$ \\
\hline CT (TC) & 1193 & 1145 & 1099 & 1288 & 1102 & 23,3 & $\hat{\mathrm{Y}}=11,66$ \\
\hline FDN (NDF) & 704 & 678 & 663 & 800 & 710 & 23,2 & $\hat{\mathrm{Y}}=712$ \\
\hline CNF (NFC) & 488 & 466 & 435 & 487 & 391 & & $\hat{\mathrm{Y}}=453$ \\
\hline NDT (TDN) & \multicolumn{6}{|c|}{ Intake, \% BW } & $\hat{\mathrm{Y}}=854$ \\
\hline MS (DM) & 3,19 & 2,90 & 2,99 & 3,18 & 2,88 & 18,6 & $\hat{\mathrm{Y}}=3,03$ \\
\hline MO (OM) & 3,05 & 2,76 & 2,84 & 3,02 & 2,73 & 18,6 & $\hat{\mathrm{Y}}=2,88$ \\
\hline $\mathrm{CT}(\mathrm{TC})$ & 2,64 & 2,39 & 2,46 & 2,63 & 2,37 & 18,6 & $\hat{\mathrm{Y}}=2,50$ \\
\hline FDN (NDF) & 1,55 & 1,41 & 1,49 & 1,63 & 1,52 & 18,6 & $\hat{\mathrm{Y}}=1,52$ \\
\hline CNF (NFC) & 1,08 & 0,97 & 0,97 & 0,99 & 0,84 & 19,0 & $\hat{\mathrm{Y}}=0,97$ \\
\hline
\end{tabular}

MO, PB, EE, CT, FDN, CNF e NDT: matéria orgânica, proteína bruta, extrato etéreo, carboidratos totais, fibra em detergente neutro, carboidratos não-fibrosos, e nutrientes digestíveis totais.

$O M, C P, E E, T C, N D F, N F C, T D N$ : organic matter, crude protein, ether extract, total carbohydrate, neutral detergent fiber, non fiber carbohydrate, and total digestible nutrients.

encontrando-se valores médios de 1.166, 711 e $453 \mathrm{~g}$ e de 2,$5 ; 1,52$ e $0,97 \%$ do PV, respectivamente. O consumo médio de MS, de 3,03\% do PV, observado para as diferentes dietas, propiciou um consumo de FDN de 1,52\% do PV.

Verificou-se efeito linear $(\mathrm{P}<0,05)$ dos níveis de casca de café sobre o consumo médio de EE, estimando-se redução de 0,528 g para cada unidade de casca adicionada. Embora a casca tenha apresentado valor de NDT (Tabela 2) muito inferior ao do NDT do milho (Valadares Filho, 2001), a análise de regressão não detectou efeito dos níveis de casca de café sobre os consumos diários de NDT, obtendo-se valor médio de $854 \mathrm{~g}$.

Os coeficientes de digestibilidade aparente da MS, MO, CT, FDN, CNF, PB e EE e a concentração de nutrientes digestíveis totais observados ( $\mathrm{NDT}_{\mathrm{OBS}}$ ) e estimados ( $\mathrm{NDT}_{\mathrm{EST}}$ ) são apresentados na Tabela 4. As digestibilidades aparentes da MS, MO, PB não foram alteradas pela adição de casca de café nas dietas, observando-se valores médios de 60,1; 62,1 e $66,3 \%$. Os baixos valores de digestibilidade da MS e baixa concentração de NDT das dietas podem ser atribuídos, em grande parte, ao baixo valor nutritivo do volumoso utilizado, caracterizado pelos elevados teores de FDN e de nitrogênio ligado à fração fibrosa e pelos baixos teores de PB (Tabela 2).

As digestibilidades aparentes de CT, FDN e CNF não foram alteradas pela adição de casca de café nas dietas, encontrando-se valores médios de 61,5; 46,9 e $84,1 \%$, respectivamente. Uma vez que boa parte do $\mathrm{N}$ da casca de café está ligada aos componentes da 
Tabela 4 - Valores médios dos coeficientes de digestibilidade e nutrientes digestíveis totais observados (NDT OBS) e estimados (NDT ${ }_{E S T}$ ) em função dos níveis de casca de café na ração concentrada (base da MS), com suas respectivas equações de regressão

Table 4 - Mean values of coefficients of digestibility and total digestible nutrients observed (TDN OBSS $_{\text {) and }}$ estimated (TDN EST $_{\text {) }}$ in function of coffee hulls levels on concentrate rations (DM base), coefficients of variation and regression equations

\begin{tabular}{|c|c|c|c|c|c|c|c|}
\hline \multirow[t]{2}{*}{$\begin{array}{l}\text { Itens } \\
\text { Items }\end{array}$} & \multicolumn{5}{|c|}{$\begin{array}{l}\text { Dietas } \\
\text { Diets }\end{array}$} & \multirow[t]{2}{*}{$\mathrm{CV}$} & \multirow[t]{2}{*}{$\begin{array}{l}\text { Equações de regressão } \\
\text { Regression equations }\end{array}$} \\
\hline & 0,0 & 6,25 & 12,5 & 18,75 & 25,0 & & \\
\hline CDMS (DCDM) & 60,8 & 61,2 & 60,8 & 58,2 & 60,0 & 3,9 & $\hat{\mathrm{Y}}=60,01$ \\
\hline CDMO (DCOM) & 62,7 & 63,2 & 62,7 & 59,9 & 62,0 & 3,9 & $\hat{\mathrm{Y}}=62,1$ \\
\hline CDPB (DCCP) & 67,3 & 67,4 & 66,5 & 63,6 & 66,8 & 5,6 & $\hat{\mathrm{Y}}=66,3$ \\
\hline $\operatorname{CDEE}(D C E E)$ & 73,9 & 65,9 & 73,8 & 58,3 & 61,9 & 10,4 & $\hat{\mathrm{Y}}=73,11-0,5078 \mathrm{X}\left(\mathrm{r}^{2}=0,51\right)$ \\
\hline CDCT (DCTC) & 61,9 & 62,7 & 61,9 & 59,5 & 61,5 & 4,6 & $\hat{\mathrm{Y}}=61,5$ \\
\hline CDFDN (DCNDF) & 46,4 & 47,7 & 46,7 & 44,8 & 49,0 & 8,7 & $\hat{\mathrm{Y}}=46,9$ \\
\hline CDCNF (DCNFC) & 83,8 & 84,1 & 85,4 & 83,4 & 83,7 & 4,5 & $\hat{\mathrm{Y}}=84,1$ \\
\hline $\mathrm{NDT}_{\mathrm{OBS}}{ }^{1}\left(T D N_{O B S}\right)$ & 62,1 & 61,8 & 61,6 & 58,1 & 59,8 & $3,8^{\prime}$ & $\hat{Y}=62,63-0,1326 X\left(r^{2}=0,60\right)$ \\
\hline $\mathrm{NDT}_{\mathrm{EST}^{2}}{ }^{2}\left(T D N_{E S T}\right)$ & 67,2 & 66,3 & 65,1 & 64,3 & 62,6 & - & - \\
\hline
\end{tabular}

1 Valores observados (Observed values); 2 Valores estimados (Estimated values).

CDMO, CDPB, CDEE, CDCT, CDFDN, CDCNF e NDT - Coeficientes de digestibilidade da matéria orgânica, proteína bruta, extrato etéreo, carboidratos totais, fibra em detergente neutro, carboidratos não-fibrosos e nutrientes digestíveis totais, respectivamente.

$O M, C P, E E, T C, N D F, N F C, T D N$ - Digestibility coefficients of the organic matter, crude protein, ether extract, total carbohydrate, neutral detergent fiber, non fiber carbohydrate, and total digestible nutrients, respectively.

fração fibrosa na forma de NIDN e NIDA (Tabela 2), considerados de baixa disponibilidade para os microrganismos ruminais (Licitra et al., 1996; Van Soest \& Mason, 1991) e a fração fibrosa deste resíduo ter apresentado elevados teores de lignina (Tabela, 2), fator primário a limitar a digestibilidade da parede celular (Jung \& Allen, 1995), esperava-se redução na digestibilidade da fração protéica e da fibra, com conseqüente redução na digestibilidade da MS, à medida que os níveis de casca de café fossem aumentados na dieta, fato este não verificado.

Verificou-se efeito linear $(\mathrm{P}<0,05)$ dos níveis de casca de café sobre a digestibilidade aparente do EE e concentração de $\mathrm{NDT}_{\mathrm{OBS}}$, estimando-se redução de 0,507 e 0,132 unidades para cada unidade de casca de café adicionada na ração concentrada, respectivamente. Uma vez que o consumo e a digestibilidade dos nutrientes, excetuando a do EE, não tenham sido diferentes, a menor concentração de NDT registrada para as dietas com casca de café foi atribuída ao menor consumo e digestibilidade verificado para aquele nutriente. Apesar de não ter havido diferença signi- ficativa, observou-se tendência de menor consumo de CNF para as dietas com casca de café (Tabela 3), fato que pode ter contribuído para a redução do conteúdo de NDT destas dietas. Os valores médios de NDT EST para as diferentes dietas foram superiores aos de $\mathrm{NDT}_{\text {OBS }}$ (Tabela 4), resultado parcialmente explicado pelo fato de os valores de $\mathrm{NDT}_{\mathrm{EST}}$ terem sido calculados considerando consumo em nível de mantença, conforme equação descrita pelo NRC (2001).

\section{Conclusões}

A casca de café, resíduo proveniente do beneficiamento do grão de café pelo método de via-seca, quando adicionada em até $25 \%$ da MS em substituição ao fubá de milho da ração concentrada de carneiros adultos, o que corresponde a $10 \%$ de inclusão de casca de café na MS da dieta total, não comprometeu o consumo e a digestibilidade dos nutrientes da dieta, indicando a possibilidade de uso na dieta desses animais como alimento alternativo. 


\section{Literatura Citada}

ANUÁRIO ESTATÍSTICO DO BRASIL. Aspectos das atividades agropecuária e extração vegetal. v.60, seção 3, p.1-46, Rio de Janeiro, 2000.

BAIÃO, A.F. Desempenho de novilhos Nelore suplementados a pasto com diferentes níveis de concentrado. Lavras: Universidade Federal de Lavras, 2002. 43p. Dissertação (Mestrado em Zootecnia) - Universidade Federal de Lavras, 2002.

BARCELOS, A.F.; ANDRADE, I.F.; VON TIESENHAUSEN, I.M.E.V. et al. Aproveitamento da casca de café na alimentação de novilhos confinados - resultados do primeiro ano. Revista Brasileira de Zootecnia, v.26, n.6, p.1208-1214, 1997.

BÁRTHOLO, G.F.; MAGALHÃES, A.A.R.; GUIMARÃES, P.T.G. et al. Cuidados na colheita, no preparo e no armazenamento do café. Informe Agropecuário, v.14, n.162, p.33-44, 1989.

GARCIA, I.F.F.; PEREZ, J.R.O.; TEIXEIRA, J.C. et al. Desempenho de cordeiros Texel x Bergamácia, Texel x Santa Inês e Santa Inês puros, terminados em confinamento, alimentados com casca de café como parte da dieta. Revista Brasileira de Zootecnia, v.29, n.2, p.564-572, 2000.

JUNG, H.G.; ALLEN, S. Characteristics of plant cell walls affecting intake and digestibility of forages by ruminants. Journal of Animal Science, v.73, p.2774-2790, 1995.

LICITRA, G.; HERNANDEZ, T.M.; Van SOEST, P.J. Standardization of procedures for nitrogen fractionation of ruminant feeds. Animal Feed Science and Technology, v.57, n.4, p.347-358, 1996.

NATIONAL RESEARCH COUNCIL - NRC. Nutrient requirements of sheep. New York: 1985. 99p.

NATIONAL RESEARCH COUNCIL - NRC. Nutrient requirements of dairy cattle. 7.ed. Washington, D.C.: National Academy Press, 2001. 381p.

OLIVEIRA, S.L. Avaliação da casca de café melosa em rações para suínos em terminação. Lavras: Universidade Federal de Lavras, 2001. 74p. Dissertação (Mestrado em Zootecnia) - Universidade Federal de Lavras, 2001.

SILVA, D.J.; QUEIROZ, A.C. Análise de alimentos: métodos químicos e biológicos. 3.ed. Viçosa, MG: Universidade Federal de Viçosa, 2002. 235p.
SNIFFEN, C.J.; O’CONNOR, J.D.; Van SOEST, P.S. et. al. A net carbohydrate and protein system for evaluating cattle diets. II. Carbohydrate and protein availability. Journal of Animal Science, v.70, n.11, p.3562-3577, 1992.

SOUZA, A.L.; GARCIA, R.; PEREIRA, O.G. et al. Valor nutritivo da casca de café tratada com amônia anidra. Revista Ceres, v.49, n.286, p.669-681, 2002.

SOUZA, A.L.; BERNARDINO, F.S.; GARCIA, R. et al. Valor nutritivo da silagem de capim-elefante (Pennisetum purpureum Schum.) com diferentes níveis da casca de café. Revista Brasileira de Zootecnia, v.32, n.4, p.828-833, 2003.

TOWNSEND, C.R.; MAGALHÃES, J.A.; COSTA, N.L. et al. Utilização da casca de café na alimentação de ovinos deslanados. In: REUNIÃO ANUAL DA SOCIEDADE BRASILEIRA DE ZOOTECNIA, 35., 1998, Botucatu. Anais... Botucatu: SBZ, 1998. p.149-151.

UNIVERSIDADE FEDERAL DE VIÇOSA - UFV. 1997. SAEG - Sistema de análises estatísticas e genéticas. Versão 7.1. Viçosa, MG. 150p. (Manual do usuário).

VALADARES FILHO, S.C.; ROCHA JR., V.R.; CAPPELLE, E.R. Tabelas brasileiras de composição de alimentos para bovinos. Viçosa, MG: Universidade Federal de Viçosa, 2001. 297p.

Van SOEST, P.J.; MASON, V.C. The influence of Maillard reaction upon the nutritive value of fibrous feeds. Animal Feed Science and Technology, v.32, n.1, p.45-53, 1991.

VILELA, F.G. Uso da casca de café melosa em diferentes níveis na alimentação de novilhos confinados. Lavras: Universidade Federal de Lavras, 1999. 46p. Dissertação (Mestrado em Zootecnia) - Universidade Federal de Lavras, 1999.

Recebido em: 25/08/03 Aceito em: 05/04/04 